\title{
Üniversitelere Ait İnternet Web Sitelerinin Ortodonti Hastaları Için Sağladığı Bilgi Kalitesinin Değerlendirilmesi
}

\author{
Taner Öztürk(0000-0003-1670-286X) ${ }^{\alpha}$
}

Selcuk Dent J, 2021; 8: 106-112 (Doi: 10.15311/selcukdentj.741264)

Bașvuru Tarihi: 22 Mayıs 2020 Yayına Kabul Tarihi: 18 Ocak 2021

Öz

Üniversitelere Ait Internet Web Sitelerinin Ortodonti Hastaları İçin Sağladığı Bilgi Kalitesinin Değerlendirilmesi

Amaç: Bu çalışmanın amacı üniversitelere ait web sitelerinin ortodontik bilgi kaynağı yönünden kalitesini ve içeriğini değerlendirmektir.

Gereç ve Yöntemler: Google arama motoru ile "diş hekimliği fakültesi" anahtar kelimesi kullanılarak 2020 yılı Nisan ayı sonunda bir internet araması yapılmıştır. Arama sonrasında ilk 60 üniversite diş hekimliği fakültesi web sitesi değerlendirilmiştir. Ayrıca ilk 15 devlet ve vakıf üniversitesine ait diş hekimliği fakültesi ortodonti web sitesi değerlendirilerek karşılaştırma yapılmıştır. $\mathrm{Bu}$ web sitelerinin sağladığı bilginin değerlendirilmesi amacıyla üç farklı değerlendirme metodu (JAMA, DISCERN ve EQIP) kullanılmıştır.

Bulgular: JAMA kriterlerine göre yazarlık (\%95) ve patent hakkı $(\% 98,3)$ kriterlerine en çok uyulurken, kaynakça kriterinin $(\% 3,3)$ en düşük seviyede yer aldığı belirlenmiştir. DISCERN kriterlerine göre yapılan değerlendirmede Bölüm 1 skorunun 19,4 $\pm 9,37$, Bölüm 2 skorunun 13,8 $\pm 7,94$, Bölüm 3 skorunun 1,98 $\pm 1,23$ ve toplam skorun $35,28 \pm 17,84$ olduğu belirlenmiştir. DISCERN kriterlerine göre web sitelerinin bilgi sağlama kalitesi düşüktür. EQIP kriterlerine göre yapılan değerlendirmede toplam skor $\% 32,81 \pm 24,64$ olarak elde edilirken skorların en fazla oranda hayır cevabı aldığı belirlenmiş̧ir.

Sonuç: Güncel bilgilerin ve tedavilerin sağlanması için bilimsel yöntemlerin takip edildiği ve uygulandığı üniversite hastanelerine ait web sitelerin hastaların kaliteli ve doğru bilgi alabilmesi için sürekli ve belirli kriterlere göre düzenlenmesi gerektiği sonucuna varılmıştır.

\section{ANAHTAR KELIMELER}

Diş Hekimliği Fakültesi, İnternet, Ortodonti

Sağlık ile ilgili bilgiler, internette en sık aranan konular arasındadır ve hem sağlık uzmanları hem de hastalar tarafından internetin bir bilgi kaynağı olarak kullanımı giderek artmaktadır., ${ }^{1,2}$ Zaman kısıtlaması ve herhangi bir maliyet olmaksızın bilgisayarlardan akıllı telefonlara kadar birçok araç ile kolayca erişim sağlanması interneti dünya çapında popüler bir bilgi kaynağı haline getirmiştir. ${ }^{3}$ Milenyumdan önce internet, yeni müşteriler çekmek için ticari şirketler tarafından tasarlanan dijital broşür ve tanıtımların dağıtımı için çevrimiçi bir veri tabanı olarak kullanılmaktaydı. Ancak 2000'li yılların başından itibaren teknolojinin gelişmesi ve bilgisayar ve akıllı telefonların kullanımının artışıyla

\section{ABSTRACT}

Evaluation of the Information Quality Provided by University Internet Websites for Orthodontic Patients

Background: The purpose of this study is to evaluate the quality and content of the websites of university dental faculties in terms of orthodontic information source.

Methods: An internet search was carried out in April 2020 using the keyword "faculty of dentistry" using the Google search engine. After the search, the first 60 university dentistry faculty websites were evaluated. In addition, a comparison was made by evaluating the orthodontics website of the faculty of dentistry belonging to the first 15 state and foundation universities. Three different evaluation methods (JAMA, DISCERN and EQIP) were used to evaluate the information provided by these websites.

Results: According to the JAMA criteria, the authorship (95\%) and ownership (98.3\%) were observed most, while the principle of attribution (3.3\%) was found to be at the lowest level. In the evaluation made according to DISCERN criteria, it was determined that the Part- 1 score was $19.4 \pm 9.37$, the Part-2 score was $13.8 \pm 7.94$, the Part-3 score was $1.98 \pm 1.23$ and the total score was $35.28 \pm 17.84$. According to DISCERN criteria, websites provide poor information quality. In the evaluation according to the total score of the scores was obtained by EQIPscore $\% 32.81 \pm 24.64$ was determined as a maximum ratio of no answer received.

Conclusion: It is concluded that the websites of university hospitals where scientific methods are followed and applied in order to provide up-to-date information and treatments should be arranged continuously and according to certain criteria in order for patients to receive quality and accurate information.

\section{KEYWORDS}

Dental Faculty, Internet, Orthodontics

internet ortamı farklı konulardaki inceleme, yorum, yazı ve görsellerin yer aldığı her alanda kullanıcıların başlıca erişim kaynağı olmaya başlamıştır. ${ }^{4}$ Uluslararası Telekomünikasyon Birliği verilerine göre 2002 yılından 2019 yılına kadar dünya çapındaki internet kullanıcı sayısının 677 milyon insandan $(\% 13,4) 4$ milyar insana (\%57) çıkması ile internet kullanım oranı da 6 kat artmıştır. Bu kullanım oranı özellikle gelişmekte olan ülkelerde \%4,6'dan \%46,7'ye (10 katına) kadar yükselmiştir. ${ }^{5}$ Diğer taraftan Türkiye İstatistik Kurumu verilerine göre ülkemizdeki internet kullanım oranları 2005 yılında \%17,6 iken 2019 yılında \%75,3'e yükselmiştir. ${ }^{6} \mathrm{Bu}$

\footnotetext{
${ }^{\alpha}$ Erciyes Üniversitesi, Diş Hekimliği Fakültesi, Ortodonti AD, Kayseri, Türkiye
} 
veriler bize internet kullanımının giderek arttığını göstermektedir.

Geleneksel olarak, ortodontik tedaviye intiyaç duyan bir kişi ortodontist tarafından yapılan muayene ile kendisinde bulunan ortodontik maloklüzyon hakkında doğrudan bilgilendirilir. Tedavi olma konusunda istekli olan hastaların tedavileri ise muayenehane, ağız ve diş sağlığı kliniği veya diş hekimliği fakültesi gibi birimlerde ortodonti uzmanları tarafından gerçekleştirilir. Ülkemizde sosyal devlet yapısı sayesinde ortodontik tedaviler sağlık sigortası tarafından karşılanmaktadır. ${ }^{7} \mathrm{Bu}$ nedenle ortodontik bir maloklüzyona sahip hastaların birçoğu tedavi olmadan önce sıklıkla devlet kurumlarına başvurmaktadır. Bununla birlikte, günümüzde herhangi bir tedavi ihtiyacı olan kişilerin birçoğu herhangi bir profesyonel yardıma başvurmadan önce sağlık problemleri ve tedavileri hakkında internet üzerinden araştırma yapmakta ve konu ile ilgili bilgi edinmeye çalışmaktadır. Bu sebeple internet ortamındaki bilgilerin kalitesi, güvenilirliği ve doğruluğu kritik öneme sahiptir. Insanların internet üzerinden sağlık ilgili bilgilere sıkça araştırma yapması web sitelerinin bilgi içeriğini değerlendiren farklı kriterler geliştirilmiştir. Bu kriterlerden bir olan ve Amerika Medikal Birliği tarafından yayınlanan Journal of American Medical Association (JAMA) kriterleri başlangıçta yalnızca sağlıkla ilgili yazılı yayınların değerlendirilmesinde kullanılırken günümüzde internet sitesi kaynaklarının değerlendirilmesi amacıyla da kullanılmaktadır. ${ }^{8-10}$ Benzer şekilde 1999 yılında Oxford Üniversitesi'nde geliştirilen 16 soruluk Tüketici Sağlığı Bilgileri İçin Kalite Kriterleri (Quality Criteria for Consumer Health Information - DISCERN) başlangıçta yazılı bilgi kaynaklarının kalitesini değerlendirmede kullanılırken günümüzde web kaynaklı bilgi içeriklerinin kalitesinin değerlendirilmesinde kullanılmaktadır.,11 Hasta için Kalite Bilgilerinin Sağlanması (Ensuring Quality Information for Patients - EQIP) kriterleri ise, tüm yazılı sağlık kaynaklarında yer alan bilgilerin kalitesini değerlendirmek için tasarlanmış güncel bir sistemdir. ${ }^{12,13}$

$\mathrm{Bu}$ nedenlerle çalışmamızın amacı ortodonti alanında araştırma, eğitim ve tedavi hizmeti sağlayan güncel araştırma ve teknolojilerin takibinin sağlandığı diş hekimliği fakültelerinin ortodonti anabilim dallarına ait web sitelerinin sağladığı ortodontik bilgi kalitesinin internet üzerinden kolayca ve ücretsiz bir şekilde erişilebilen üç farklı değerlendirme kriteri kullanılarak incelenmesidir.

\section{GEREÇ VE YÖNTEMLER}

$\mathrm{Bu}$ çalışma halka açık olan Google internet arama motoru (Google Search, Alphabet, ABD) kullanılarak 2020 yılı Nisan ayı sonunda gerçekleştirilmiştir. Arama öncesinde konum kaynaklı hataların ortadan kaldırılması için arama yapılan internet sağlayıcısının (Internet Explorer, Microsoft Inc., Redmond, WA, ABD) ve bilgisayarın konum ve çerez servisleri kapatılmıştır. Google arama motoruna "diş hekimliği fakültesi" anahtar kelimesi girilerek yalnızca Türkçe ve Türkiye merkezli üniversite web siteleri için internet sitesi taraması gerçekleştirilmiştir. İnternet taraması diş hekimliği fakültelerine ait toplam 60 web sitelerinde yer alan ortodonti anabilim dalı bilgilendirme-tanıtım sayfaları değerlendirmeye alınmıştır. Çalışmada bu örnek sayısının seçilmesinin nedeni internet araması yapan kullanıcıların \%95'inin ilk 3 sayfadaki 50 sonuca odaklanmalarıdır. ${ }^{14}$ Çalışmada örneklem gücünün arttırılması için 60 sonuç değerlendirilmiştir. Bununla birlikte devlet üniversiteleri ve vakıf/özel üniversitelerin diş hekimliği fakültelerine ait ortodonti anabilim dalı web sayfalarında yer alan bilgilerin kalitesi karşılaştırmalı olarak değerlendirilmiştir. Bu amaçla her iki grup için internet taraması sırasında ilk 15 seçenekte görülen diş hekimliği fakültesi web siteleri değerlendirmeye alınmıştır. Çalışmaya dahil edilen web sayfaları uzman bir hekim (ortodontist) tarafından 'Journal of American Medical Association (JAMA)'9, Tüketici Sağlığı Bilgileri İçin Kalite Kriterleri (DISCERN) ${ }^{10}$ ve Hasta için Kalite Bilgilerinin Sağlanması (EQIP) ${ }^{12}$ kriterleri kullanılarak değerlendirilmiştir.

Amerikan Medikal Birliği Dergisi (Journal of American Medical Association - JAMA) Kriterleri

Silberg ve arkadaşları tarafından sağlık ile ilgili yazılı bilgi kaynaklarından elde edilen bilgilerin standartlarının değerlendirilebilmesi için JAMA kriterlerinin kullanılması önerilmiştir. ${ }^{9}$ Bu kriterler ile bir sağlık bilgi kaynağı/web sitesi için açıkça görülmesi gereken dört temel özellik (yazarlık, kaynakça, patent hakkı, güncellik) değerlendirilir. Değerlendirme yapılırken her bir kriterin açıkça belirtilmesine dikkat edilmelidir. JAMA kriterlerinin değerlendirilmesi ile alınacak en düşük skor değeri 0 iken en yüksek skor değeri 4 olarak belirlenmiştir. Her bir web sitesi tek tek incelenerek bu kriterleri sağlayan her bir maddeye "1" skor değeri verilerek puanlama yapılmıştır.

Tüketici Sağlığı Bilgileri İçin Kalite Kriterleri (Quality Criteria for Consumer Health Information - DISCERN)

Hastalar ve bilgi sağlayıcıları tarafından sağlık alanındaki yazılı bilgilerin kalitesinin değerlendirilmesinde kullanılan DISCERN kriterleri, Charnock ve arkadaşları tarafından geliştirilmiş ve sunulmuştur. ${ }^{11}$ DISCERN değerlendirme tablosu toplamda 16 soru ve 3 bölümden (1. Bölüm: güvenilirlik, 1-8. Sorular; 2. Bölüm: tedavi seçenekleri, 9-15. Sorular; ve 3. Bölüm: genel puan, 16. soru) oluşmaktadır. Her bir soruya "1" (hayır) ile "5" (evet) arasında bir skor değeri verilmektedir. Değerlendirme sonunda skorlar güvenilirlik bölümü için "8 ile 40" arasında, tedavi seçenekleri bölümü için "7 ile 35 " arasında ve web sitesinin bir bütün olarak değerlendirildiği genel skor 
bölümü için ise "1 ile 5" arasında olmaktadır. Tüm değerlendirmeler sonunda elde edilen DISCERN toplam skoru ise "16 ile 80" arasında olmaktadır. Toplam DISCERN skoruna göre "16 ile 26 " skor değeri aralığı "çok zayıf", "27 ile 38" skor değeri aralığı "zayıf”, "39 ile 50" skor aralığı "makul”, "51 ile 62" skor değeri aralığı "iyi" ve "63" üzeri skor değerleri ise "mükemmel" kalite olarak nitelendirilmektedir. ${ }^{8,14}$

Hasta için Kalite Bilgilerinin Sağlanması (Ensuring Quality Information for Patients - EQIP)

Moult ve arkadaşları tarafından önerilen yazılı olarak sunulan sağlık bilgilerinin değerlendirilmesi için kullanılan EQIP formu güvenilirlik, geçerlilik ve fayda sağlayan 20 sorudan oluşmaktadır. ${ }^{12} \mathrm{Bu}$ formda kullanılan derece ölçeği yüzde (\%) olarak gösterilmektedir ve skorlar "0 ile 100" arasında değişmektedir. Yüksek değerler web sitesi tarafından sağlanan bilginin kalitesinin iyi olduğunu göstermektedir. ${ }^{16}$ Her bir soru için 4 skor değeri (Evet, Kısmen, Hayır, Uygulanmıyor \& Nedeni) tanımlanmaktadır. Her bir soruya verilen skorlar ile formun doldurulmasından sonra total skor şu şekilde hesaplanmaktadır:

$[($ Evet $x$ 1) $+($ KIsmen $\times 0.5)+($ Hayır $\times 0) /(20-$ Uygulanmıyor \& Neden)] $x 100=\%$ skor

\section{isTATISTiKSEL DEĞERLENDIRME}

Verilerin kaydedilmesi için Microsoft Office Excel (Microsoft Office 365; Microsoft Inc., Redmond, WA, ABD) programı kullanılmıştır. Elde edilen verilerin analizi Stata istatistiksel analiz programı (StataCorp. 2017. Stata Statistical Software: Release 15. College Station, TX: StataCorp LLC) kullanılarak gerçekleştirilmiştir. Değerlendirme sonucunda elde edilen toplam skorlar, ortalama \pm standart sapma, \%95 güven aralığının alt ve üst sınırları şeklinde verilmiş ve her bir soru için cevaplar yüzde olarak belirtilmiştir. Elde edilen sayısal verilerin normal dağılım analizi için Shapiro Wilks testi kullanılmıştır. Normal dağılım göstermediği belirlenen verilerin analizinde Mann Whitney-U testi kullanılmıştır. Değerlendirme metotları arasındaki korelasyonun incelenmesi amacıyla Spearman katsayısı kullanılmıştır. İstatistiksel anlamlılık değeri $p<0,05$ olarak alınmıştır.

\section{BULGULAR}

Bu kesitsel tanımlayıcı araştırma sonucunda internet taraması ile karşımıza çıkan diş hekimliği fakültesi web sitelerinden ilk 60 tanesi değerlendirmeye alınmıştır. $\mathrm{Bu}$ diş hekimliği fakültelerinden 42'si (\%70) devlet üniversitesine, 18'i (\%30) vakıf (özel) üniversitesine ait olan kurumlardır. Üniversitelerin illere göre dağılımı incelendiğinde en fazla sayıda diş hekimliği fakültesinin İstanbul'da $(\% 21,70)$ olduğu tespit edilmiştir.
JAMA kriterlerine göre yapılan değerlendirmede tüm JAMA kriterlerine uyan bir web sitesi bulunamamıştır. JAMA kriterleri içerisinde en çok uyulan Yazarlık (\%95) ve Patent hakkı $(\% 98,3)$ kriterleri iken en az uyulan kriterin Kaynakça ilkesinin $(\% 3,30)$ olduğu belirlenmiştir (Şekil 1).

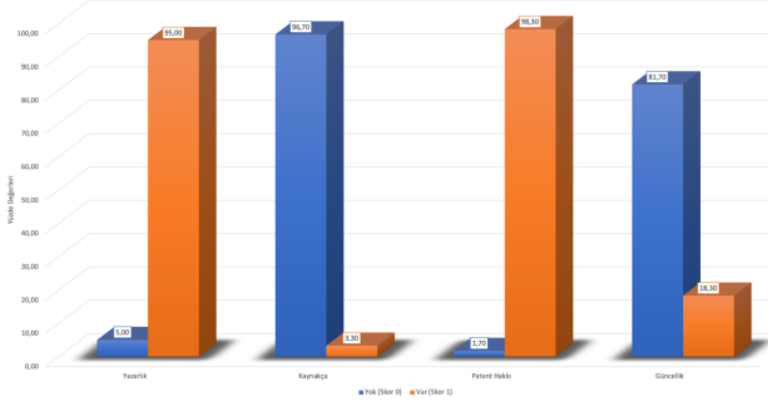

Şekil 1

JAMA kriterlerine göre ilkeye bağlı web sitelerinin yüzdesi

Genel olarak ise JAMA skorunun 2,15 \pm 0,40 (\%95 Güven Aralığı (GA)'na göre 2,05 - 2,25) olduğu tespit edilmiştir (Tablo 1). DISCERN kriterlerine göre yapılan değerlendirmede güvenilirlik (Bölüm 1) skorunun 19,4 \pm 9,37 (\%95 GA'na göre 17,10 - 21,90), tedavi seçenekleri (Bölüm 2) skorunun 13,8 \pm 7,94 (\%95 GA'na göre 11,77 - 15,83), genel puan (Bölüm 3) skorunun 1,98 $\pm 1,23$ (\%95 GA'na göre 1,67 - 2,30) ve toplam skorun 35,28 $\pm 17,84$ (\%95 GA'na göre 30,71 39,85 ) olduğu tespit edilmiştir (Tablo 1).

Tablo 1.

JAMA, DISCERN ve EQIP skorlaması sonrası elde edilen verilerin tanımlayıcı değerleri.

\begin{tabular}{|c|c|c|c|c|c|c|}
\hline & & & & & \multicolumn{2}{|c|}{ \%95 güven aralığı } \\
\hline & $N$ & $\begin{array}{l}\text { Normal } \\
\text { Değer }\end{array}$ & Ort. & S.S. & Alt Sinır & Üst Sınır \\
\hline JAMA & 60 & $0-4$ & 2,15 & 0,4 & 2,05 & 2,25 \\
\hline $\begin{array}{l}\text { DISCERN } 1 . \\
\text { BÖLÜM }\end{array}$ & 60 & 14824 & 18,4 & 8,37 & 16,1 & 20,9 \\
\hline $\begin{array}{c}\text { DISCERN } 2 . \\
\text { BÖLÜM }\end{array}$ & 60 & 12966 & 12,8 & 6,94 & 10,77 & 12,83 \\
\hline $\begin{array}{c}\text { DISCERN } 3 . \\
\text { BÖLÜM }\end{array}$ & 60 & 44317 & 1,98 & 1,23 & 1,67 & 2,3 \\
\hline DISCERN & 60 & $16-80$ & 33,78 & 16,34 & 29,21 & 38,35 \\
\hline EQIP & 60 & $0-100$ & 32,81 & 24,64 & 26,5 & 39,12 \\
\hline
\end{tabular}

Verilen skorlar genel olarak değerlendirildiğinde soru 4 hariç diğer tüm sorularda elde edilen en yüksek değerler Skor 1 (Hayır) için olmuştur. Skor 4 (Evet) için değerlendirme yapıldığında en yüksek değerler 1 . $(\% 26,70), 2$. $(\% 26,70), 3$. $(\% 30,00)$ ve 14. $(\% 20,00)$ sorularda elde edilmiştir (Şekil $2 a$ ve b). 


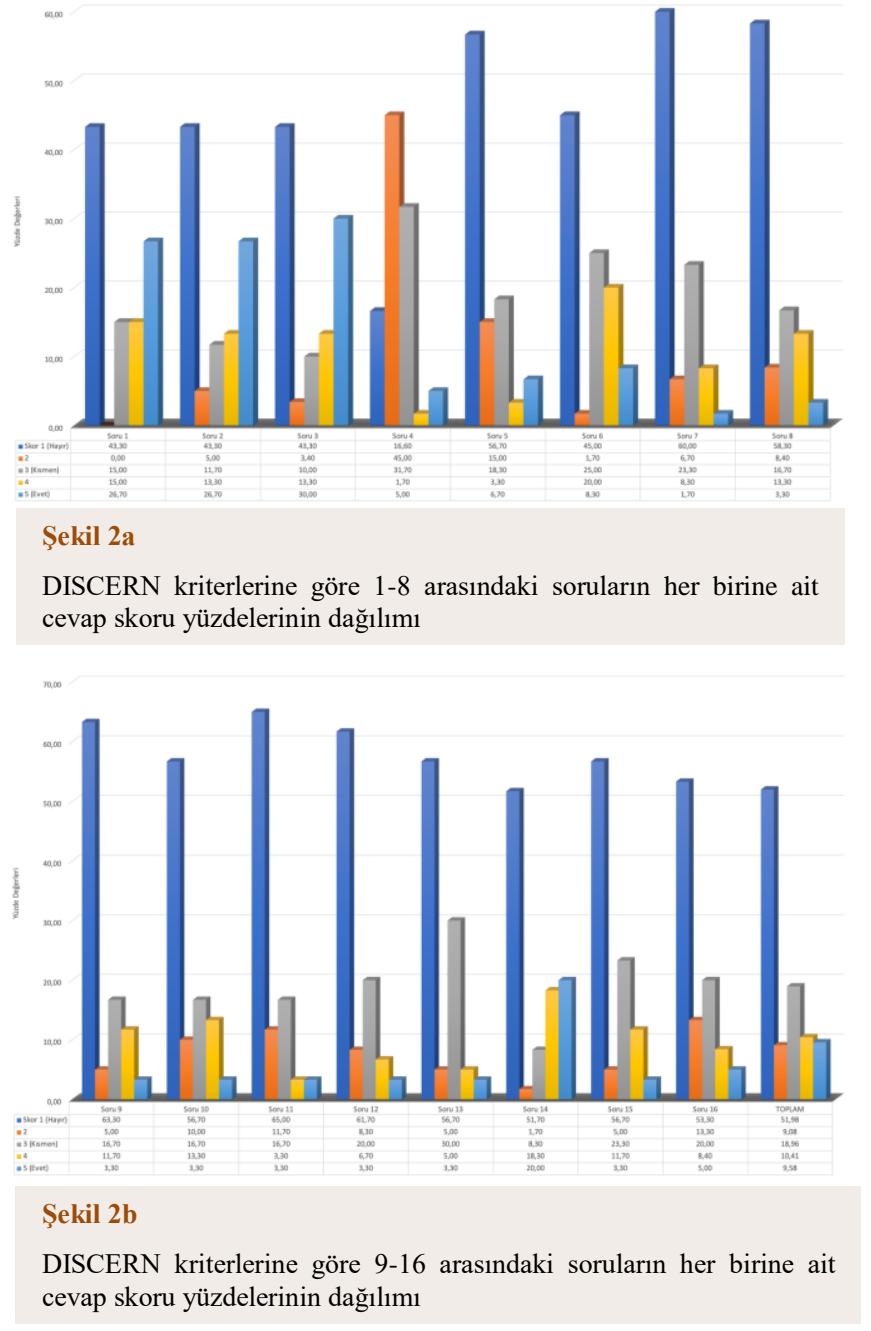

Elde edilen skor ortalaması 35,28 olduğundan üniversitelere ait web sitelerinin DISCERN kriterine göre zayıf (27 - 38 aralığında) kalitede olduğu tespit edilmiştir.

EQIP kriterlerine göre yapılan değerlendirmede toplam skor \%32,81 $\pm 24,64$ (\% 95 GA'na göre $26,50-39,12$ ) olarak elde edilmiştir (Tablo 1). Her bir soruya verilen skorlar incelendiğinde en fazla Skor 2 değerinin elde edildiği görülmektedir (Şekil 3 a ve b). Skor 1 değerlerinin ise 6. $(\% 61,70), 7$. (\% 76,70), 8. (\% 58,30), 9. $(\% 56,70)$, 11. $(\% 88,30), 13 .(\% 83,30), 14 .(\% 61,70)$, 16. $(\% 80,00)$, 17. (\% 46,70), 18. (\% 50,00), 19. (\% $63,30)$ ve 20. $(\% 68,30)$ sorularda en yüksek olduğu belirlenmiştir. En yüksek Skor 4 (Evet) değerlerinin 1. $(\% 43,30)$, 3. $(\% 35,00)$ ve 12 . ( $\% 91,70)$ sorularda olduğu tespit edilmiştir (Şekil 3 a ve b). Toplam EQIP skoru değerlendirildiğinde ise web sitelerinin düşükorta düzeyde bir bilgi kalitesi gösterdiği belirlenmiştir.

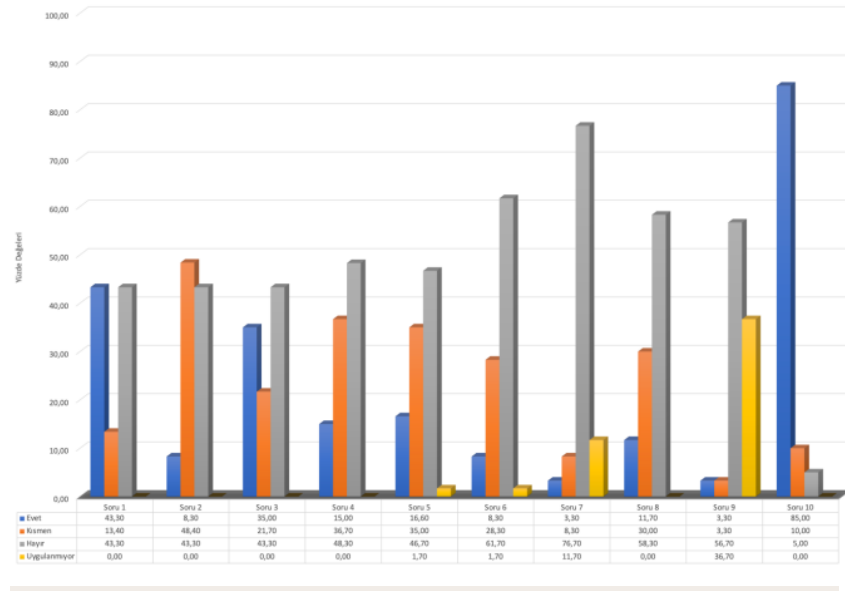

Şekil 3a

EQIP kriterlerine göre 1-10 arasındaki soruların her birine ait cevap skoru yüzdelerinin dağılımı

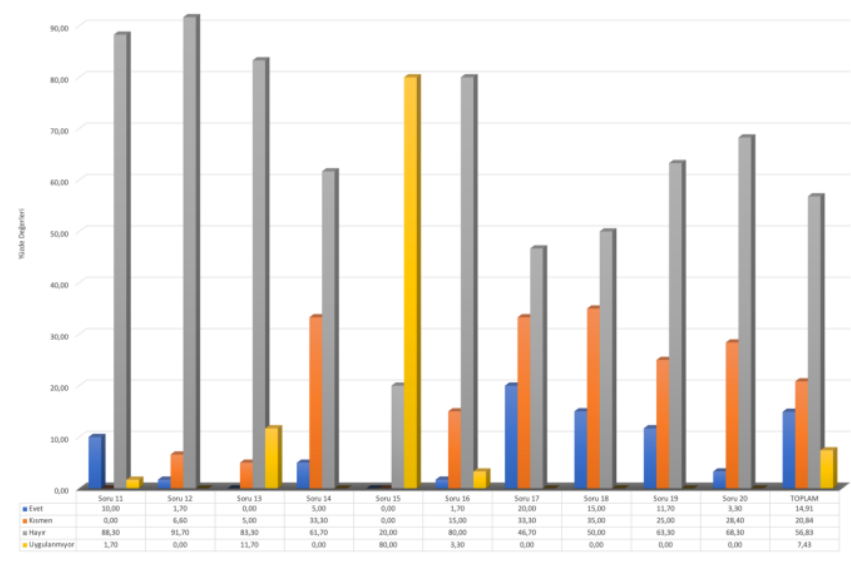

Şekil 3b

EQIP kriterlerine göre 11-20 arasındaki soruların her birine ait cevap skoru yüzdelerinin dağılımı

Değerlendirme metotları arasındaki korelasyon değerlendirildiğinde DISCERN kriterleri ile JAMA ( $r=$ $0,383, p=0,002)$ ve EQIP $(r=0,967, p<0,001)$ kriterleri arasında pozitif yönlü anlamlı bir korelasyon olduğu bulunmuştur (Tablo 2). Ancak JAMA ve EQIP kriterleri arasında anlamlı bir korelasyon olmadığı görülmüştür $(p>0,05)$.

Tablo 2.

Kalite kriterleri arasındaki korelasyonun değerlendirilmesi.

\begin{tabular}{lcc} 
& $r$ & $p$ \\
\hline DISCERN - JAMA & 0,383 & 0,002 \\
\hline DISCERN - EQIP & 0,967 & $p<0,001$ \\
\hline JAMA - EQIP & 0,329 & 0,097 \\
r: Spearman korelasyon katsaylsl. Istatistiksel anlamlllik değeri $p<0,05$ olarak alınmıştr.
\end{tabular}


Devlet ile özel üniversitelere ait web sitelerinin bilgi sağlama kalitesi karşılaştırıldığında DISCERN 1. Bölüm $(p=0,013)$, DISCERN total $(p=0,048)$ ve EQIP $(p=0,045)$ kriterlerine göre gruplar arasında istatistiksel olarak anlamlı derecede farklılık olduğu ve devlet üniversitelerine ait değerlerin daha yüksek olduğu tespit edilmiştir (Tablo 3).

\section{Tablo 3.}

Google Arama motorunda görülme sırasına göre ilk 15 sırada yer alan Devlet ve Vakıf üniversitelerinin karşısıştırıması.

\begin{tabular}{|c|c|c|c|c|c|c|c|c|c|c|c|}
\hline & \multicolumn{5}{|c|}{ Devlet Üniversiteleri } & \multicolumn{5}{|c|}{ Vakıf Üniversiteleri } & \multirow[b]{3}{*}{$\underset{*}{P}$} \\
\hline & \multirow[b]{2}{*}{$\mathrm{N}$} & \multirow[b]{2}{*}{ Ort. } & \multirow[b]{2}{*}{ S.s. } & \multicolumn{2}{|c|}{ \%95 güven aralı̆ğı } & \multirow[b]{2}{*}{$\mathrm{N}$} & \multirow[b]{2}{*}{ Ort. } & \multirow[b]{2}{*}{ S.S. } & \multicolumn{2}{|c|}{$\begin{array}{l}\text { \%95 gũven } \\
\text { aralığı }\end{array}$} & \\
\hline & & & & $\begin{array}{l}\text { Alt } \\
\text { Sinir }\end{array}$ & Üst Sınır & & & & $\begin{array}{l}\text { Alt } \\
\text { Sinir }\end{array}$ & $\begin{array}{l}\text { Üst } \\
\text { Sinir }\end{array}$ & \\
\hline JAMA & 15 & 2,13 & 0,35 & 1,93 & 2,33 & 15 & 2,1 & 0,31 & 1,87 & 2,29 & 0,972 \\
\hline $\begin{array}{l}\text { DISCERN } 1 . \\
\text { BÖLÜM }\end{array}$ & 15 & 28,47 & 5,47 & 25,43 & 31,5 & 15 & 20,33 & 8,53 & 15,61 & 25,06 & 0,013 \\
\hline $\begin{array}{l}\text { DISCERN } 2 . \\
\text { BÖLÜM }\end{array}$ & 15 & 18,13 & 8,26 & 13,56 & 22,71 & 15 & 14,4 & 7,16 & 10,43 & 18,36 & 0,225 \\
\hline $\begin{array}{l}\text { DISCERN } 3 . \\
\text { BÖLÜM }\end{array}$ & 15 & 2,8 & 1,52 & 1,96 & 3,64 & 15 & 2,07 & 1,03 & 1,49 & 2,64 & 0,168 \\
\hline DISCERN & 15 & 49,4 & 14,17 & 41,55 & 57,24 & 15 & 36,8 & 16,15 & 27,86 & 45,74 & 0,048 \\
\hline EQIP & 15 & 55,27 & 21,78 & 55,27 & 5,62 & 15 & 35,42 & 21,86 & 23,31 & 47,52 & 0,045 \\
\hline
\end{tabular}

N: Örnek sayısl, Ort:: Ortalama, S.S.: Standart Sapma. * Mann Whitney-U testi sonuçlan. istatistiksel anlamlılık değeri $p<0,05$ olarak alınmıştır.

\section{TARTIŞMA}

Günümüzde internet dünyası, diğer alanlar ile birlikte sağlık alanında da evrensel bir bilgi paylaşım platformu olmuştur. ${ }^{17}$ Son yıllarda internet ortamında sağlık hizmet bilgisi veren web sitelerinin sayısı önemli ölçüde artmıştır ancak sitelerin sağladığı bilgilerin güvenilirliğinin standartlaştırıması konusunda henüz bir fikir birliği yoktur. ${ }^{18}$ Hastalar için sağlanan ortodontik tedavi, lingual ortodonti, ortodontik retainerler, dudak-damak yarıkları veya ortognatik cerrahi tedavileri ile ilgili internet bilgi kaynaklarının güvenilirliğinin değerlendirildiği çeşitli çalışmalar vardır. $8,10,16,18-23$ Bu kapsamda çalışmamı diş hekimliği fakültelerinin hastalara ortodonti ve ortodontik tedaviler konusunda bilgi sağlama kalitesini değerlendiren ve bu alanda EQIP kriterlerini kullanan ilk çalışmadır.

İternette kolayca arama yapmaya izin veren birçok arama kaynağı olmasına rağmen, günümüzde en sık kullanılan ve diğer arama motorları ile kıyaslandığında daha fazla sayıda sonuç sağlayan tek bir arama motorundan (Google) elde edilen sonuçlar değerlendirilmiştir. ${ }^{19,24}$ İnternet üzerinden bilgi paylaşımı günümüzün sağlık hizmeti sağlayıcıları için daha fazla önem kazanmaktadır, çünkü çoğu hasta için internet kaynakları kolay ve hızlı erişilebilen bilgi kaynağı haline gelmiştir. ${ }^{20}$ Tedavi arayışında olan hastaların kaliteli ve güvenilir bilgi sunan internet kaynakları ile düşük kaliteli ve yanlış bilgi sunan internet kaynakları arasında ayrım yapması oldukça zordur. ${ }^{25} \mathrm{Bu}$ nedenle hastaların internet aracılığıyla doğru bilgi edinebileceği kaynakların varlığı oldukça önemlidir.
Diğer sağlık alanlarındaki değerlendirmeler içinde kullanılan JAMA, DISCERN ve EQIP kalite kriter formları, sağlık profesyonellerinin hastaları doğru bilgi sağlayan internet sitelerine yönlendirmelerine

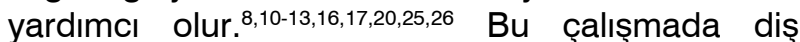
hekimliği fakülteleri bünyesinde yer alan ortodonti ana bilim dallarına ait web sitelerinin bilgilendirme kalitesi değerlendirilmiştir. Çünkü bireylerin aradıkları konu ile ilgili bilinen ve güncel resmi kurumlara olan güveni genellikle tanıtım ve reklam sağlayan özel kurumlara olan güveninden daha fazladır. ${ }^{19,27}$ Van Deursen ve Van Dijk'in çalışmasında internet kullanıcılarının genellikle arama motorundaki ilk sayfaya ve ilk 10 sıradaki internet sitesine baktıkları bildirilmiştir. ${ }^{28}$ Ayrıca Aldairy ve arkadaşları, sağlık alanında internet sayfalarının kullanılma düzeyini değerlendirdikleri çalışmasında hastaların ilk 20 sıradaki internet sitesinden daha fazlasına bakmadıklarını belirtmişlerdir. ${ }^{18} \mathrm{Bu}$ nedenle çalışmada ülke içerisindeki bölgesel farklılıklarda göz önünde bulundurularak internet motoru ile arama sonucunda ilk 60 sırada yer alan diş hekimliği fakültelerine ait web siteleri değerlendirilmiştir. Devlet veya vakıf üniversitesi olmasına göre gerçekleştirilen değerlendirme için ise daha genel bir sonuç elde edilebilmesi amacıyla ilk 15 sıradaki devlet ve vakıf üniversitelerine ait web siteleri incelenmiştir.

Internet kaynakları kullanılarak yapılan bir aramada, hastalar çoğunlukla bilgilerin kolay erişilebilir, anlaşılabilir ve yararlı olup olmamasına dikkat eder. ${ }^{20}$ Bununla birlikte internet üzerinden elde edilen bir bilgilin kolay erişilebilir ve anlaşılabilir olması bu bilgilerin doğruluğunun göstergesi değildir. Çünkü veriler herkese açık olarak erişilmeden önce doğru şekilde düzenlenmez, hatalı bilgiler çıkarılmaz veya doğruluk açısından incelenmez. Sonuç olarak günümüzde bunları değerlendiren farklı kriterlerin kullanımı giderek artmaktadır. Bu nedenle çalışmamızda daha doğru bir sonuç eldesi için daha önce çeşitli çalışmalarda kullanılan üç farklı (JAMA, DISCERN ve EQIP) değerlendirme metodu kullanılmıştır. ${ }^{8,13,16}$

Olkun ve Demirkaya'nın lingual ortodonti ile ilgili internet bilgi kaynaklarını değerlendirdikleri çalışmada da belirttiği gibi özellikle sağlık alanındaki web siteleri hazırlanırken referans alınan kaynaklar ve bilgilerin yüklendiği-güncellendiği tarihler açıkça belirtilmelidir. ${ }^{8}$ Aghasiyev ve Şen Yılmaz'ın ortodonti ile ilgili internet bilgi kaynaklarının genel olarak değerlendirildiği çalışmada ise bilgi güvenilirliğinin ve kalitesinin yeterli olmadığı ve kurumsal yapılar olan devlet kaynaklarının koordineli bir program ile daha güvenilir kaynakların eldesine katkı sağlayabileceği 
belirtilmiştir. ${ }^{19}$ Çalışmada elde edilen veriler JAMA kriterlerine göre değerlendirildiğinde web sitelerindeki en büyük eksiklik Kaynakça ve Güncellik kriterlerinde idi. IIlgili web sitelerinin eğitim verilen ve güncel araştırmaların takip edildiği üniversitelere ait olması nedeniyle bu durumun daha da büyük önem kazandığı ve geliştirilmesi gerektiği düşünülmektedir. Devlet ve vakıf üniversitelerinin ortodonti anabilim dallarına ait web siteleri karşılaştııılığında arasında ise JAMA kriterleri açısından bir farklılık olmadığı belirlenmiştir. Veriler DISCERN kriterlerine göre değerlendirildiğinde on altı kriterin on bir tanesinde yetersizlik olduğu belirlenmiştir. Benzer şekilde EQIP kriterleri ile yapılan değerlendirmelerde de 10 nolu soru hariç, tüm sorulara yönelik ciddi miktarda eksiklikler olduğu belirlenmiştir. EQIP kriterlerine göre 10 nolu kriter ortodonti kliniğin iletişim bilgileri ile ilgilidir ve birçok web sitesinde iletişim bilgileri yer almaktadır. DISCERN ve EQIP kriterlerine dahil olan sorular genellikle birbirini desteklemekle birlikte DISCERN kriterleri bilgi kaynağının daha çok bilgi yönünden kalitesini değerlendirirken, EQIP kriterleri bilgi kaynağının hem bilgi hem de bilginin okuyucu tarafından anlaşılması yönünden kalitesini değerlendirmektedir. Tüm kriterler değerlendirildiğinde sağlanan bilgiler ile ilgili olarak özellikle referans kaynakları ve bilginin düzenlendiğigüncellendiği tarih eksikliği dikkat çekmektedir. Bu nedenlerle sifır hipotezimiz reddedilmiştir. Illgili kurumların en güncel bilgileri sağlaması gerektiği düşünülmektedir. Hastaların özellikle güncel bilgiler yönünden donanımlı olan üniversitelerin web sitelerinden daha sağlıklı bilgi edinebilmesi için, ilgili sorulara aranan cevaplar doğrultusunda güncellenmeleri gerekliliği ortaya çıkmaktadır. Ayrıca üniversite tipleri arasında özellikle DISCERN 1. Bölüm, DISCERN ve EQIP kriterleri sonucunda elde edilen değerlendirmeler arasında bir farkllık olduğu ve devlet üniversitelerinin bu kriterlere göre durumda olduğu bulunmuştur.

İnternetten sağlanan bilginin kalitesi ile ilgili yapılan önceki çalışmalarda olduğu gibi bu çalışmada da web sitelerinin anlık bir görüntüsünden elde edilen sonuçlar sunulmuştur. Dinamik bir özelliği olan internet platformunda yer alan web siteleri bilginin de sürekli değişmesi ile güncellenmektedir. ${ }^{19}$ Önceki çalışmalarda internet ortamından kaynak alan bilginin kalitesinde iyileștirme yapılması yönünde bir fikir birliği olmasına rağmen bu konuda özel bir kılavuz henüz geliştirilmemiştir. ${ }^{3,18,19}$ Öte yandan, Amerikan Tabipler Birliği tarafından bildirilen web sitelerinin bilgi sağlamada izlemesi gereken kurallara benzer şekilde diş hekimliği ve ortodonti alanında da güncel çevrimiçi değerlendirme kuralları veya platformu geliştirilebilir. ${ }^{29}$

\section{SONUÇ}

$\mathrm{Bu}$ çalışmadan elde edilen sonuçlar neticesinde, sağlık ile ilgili bilgi sağlayan web sitelerinin hatalı ve eksik bilgi yönünden yayınlanma öncesi kullanılabilirlik, sağlanan bilgi kalitesi ve uygun değerlendirme araçları ile kontrol edilmesi önerilmektedir. Hastalardan elde edilecek geri bildirimler ile web siteleri üzerinden sağlanan bilgilerin üçüncü kişilerin daha kolay anlayacağı şekilde düzenlenmesi bilgilerin kolay anlaşılabilir olması yönünden avantaj sağlayacaktır. Ülkemizde önemli sayıda üniversite ve diş hekimliği fakültesi olduğu ve günümüzde ortodontik tedavilerin daha çok talep edildiği düşünüldüğünde hastaların tedavi gereksinimi nedeniyle doğru ve kaliteli bilgiye ulaşma gerekliliği önem kazanmaktadır. 


\section{KAYNAKLAR}

1. Andreassen HK, Bujnowska-Fedak MM, Chronaki CE, Dumitru RC, Pudule I, Santana S, et al. European citizens' use of E-health services: a study of seven countries. BMC public health 2007;7:53.

2. Anderson JG, Rainey MR, Eysenbach G. The impact of CyberHealthcare on the physician-patient relationship. $J$ Med Syst 2003;27:67-84.

3. Patel U, Cobourne MT. Orthodontic extractions and the Internet: quality of online information available to the public. Am J Orthod Dentofacial Orthop 2011;139:e103-9.

4. Jorgensen $\mathrm{G}$. Social media basics for orthodontists. Am J Orthod Dentofacial Orthop 2012;141:510-5.

5. ITU. Internet Usage Statistics. International Telecommunications Union. ITU Statistics (http://www.itu.int/ict/statistics) Web wite. https://www.itu.int/en/ITU-

D/Statistics/Pages/stat/default.aspx. Published 2019. Accessed 29.04.2020.

6. TüiK. Bilgisayar ve İnternet kullanım oranı, 2005-2019. Türkiye İstatistik

Kurumu. http://www.tuik.gov.tr/PrelstatistikTablo.do?istab_id =112 0. Published 2019. Accessed 29.04.2020, 2019.

7. Özyavaş S. Türkiye'de Ağız Diş Sağlığı Politikası: Mevcut Durum Analizi. Hacettepe Sağlık İdaresi Dergisi 2018;21:789-805.

8. Olkun HK, Demirkaya AA. Evaluation of Internet Information about Lingual Orthodontics Using DISCERN and JAMA Tools. Turk J Orthod 2018;31:50-4.

9. Silberg WM, Lundberg GD, Musacchio RA. Assessing, controlling, and assuring the quality of medical information on the Internet: Caveant lector et viewor--Let the reader and viewer beware. JAMA 1997;277:1244-5.

10. Olkun HK, Demirkaya AA, Aras B. The quality of Internet information on lingual orthodontics in the English language, with DISCERN and JAMA. J Orthod 2019;46:20-6.

11. Charnock D, Shepperd S, Needham G, Gann R. DISCERN: an instrument for judging the quality of written consumer health information on treatment choices. J Epidemiol Community Health 1999;53:105-11.

12. Moult $B$, Franck LS, Brady $H$. Ensuring quality information for patients: development and preliminary validation of a new instrument to improve the quality of written health care information. Health Expect 2004;7:165-75.

13. Vaona A, Marcon A, Rava M, Buzzetti R, Sartori $M$, Abbinante C, et al. Quality evaluation of JAMA Patient Pages on diabetes using the Ensuring Quality Information for Patient (EQIP) tool. Prim Care Diabetes 2011;5:257-63.

14. Desai T, Shariff A, Dhingra V, Minhas D, Eure M, Kats $M$. Is content really king? An objective analysis of the public's response to medical videos on YouTube. PLoS One. 2013;8:e82469

15. Som R, Gunawardana N. Internet chemotherapy information is of good quality: assessment with the DISCERN tool. Br J Cancer 2012;107:403-4s.

16. Göngörmüş Z, Göngörmüş $M$. Ağız-Diş Sağlığı ile İlgili Türkçe Web Sayfalarının Kalitesinin Değerlendirilmesi: Ön Çalışma. SSSJournal 2018;4(20):2631-4.
17. Swire-Thompson B, Lazer D. Public Health and Online Misinformation: Challenges and Recommendations. Annu Rev Public Health 2020;41:433-51.

18. Aldairy T, Laverick S, Mclntyre G. Orthognathic surgery: is patient information on the Internet valid? Eur J Orthod 2012;34:466-9.

19. Aghasiyev R, Yılmaz B. The Accuracy of Information about Orthodontics Available on the Internet. Turk J Orthod 2018;31:127-32.

20. Bavbek NC, Tuncer BB. Information on the Internet Regarding Orthognathic Surgery in Turkey: Is It an Adequate Guide for Potential Patients?Turk J Orthod 2017;30:78-83.

21. Mahdmina A. Orthodontic Retainer Wear: A Crosssectional Study of Information Quality Available on the Internet. J Orthod 2016;43:6.

22. Dogramaci EJ, Rossi-Fedele G. The quality of information on the Internet on orthodontic retainer wear: a cross-sectional study. J Orthod 2016;43:4758.

23. Korkmaz YN, Buyuk SK. YouTube as a PatientInformation Source for Cleft Lip and Palate. Cleft Palate Craniofac J 2020;57:327-32.

24. Eysenbach G, Powell J, Kuss O, Sa E-R. Empirical studies assessing the quality of health information for consumers on the world wide web: a systematic review. JAMA 2002;287:2691-700.

25. Powell J, Clarke A. Internet information-seeking in mental health: population survey. $\mathrm{Br} \mathrm{J}$ Psychiatry 2006;189:273-7.

26. McGoldrick D, Kielty P, Cotter C. Quality of information about maxillofacial trauma on the Internet. Br J Oral Maxillofac Surg 2017;55:141-4.

27. Yenikurtulus, $H$. Universite Kuitüphanelerinde Elektronik Bilgi Kaynaklarına Dayalı Yararlandırma Hizmeti: Istanbul Bilgi Universitesi Kutujphanesi Uygulama Örneğ [Yüksek Lisans Tezi]. I'stanbul: İstanbul Universitesi; 2007.

28. van Deursen AJAM, van Dijk JAGM. Using the Internet: Skill related problems in users' online behavior. Interact Comput 2009;21:393-402.

29. Winker MA, Flanagin A, Chi-Lum B, White J, Andrews $\mathrm{K}$, Kennett RL, et al. Guidelines for medical and health information sites on the internet: principles governing AMA web sites. American Medical Association. JAMA 2000;283:1600-6.

Yazışma Adresi:

Taner ÖZTÜRK

Erciyes Üniversitesi

Diş Hekimliği Fakültesi

Ortodonti AD.

Kayseri, Türkiye

Tel : +90 35220766 66/29100

E Posta : tanertr35@gmail.com 